\section{INDIGO CROP OF INDIA}

The official Indian Trade Journal of December 28 last published a final general memorandum of the acreage and yield of the indigo crop in $1917-18$. The report is based upon reports received from provinces containing practically the whole area under indigo in British India. The figures refer to the crop which was then marketed. The total area is estimated at 690,600 acres, ro per cent below the area in $1916-17$ which was 770,000 acres. The total yield of dye is estimated at 87,000 cwt. as against 95,700 , the yield for the previous year, or a decrease of 8 per cent. The season was not altogether favorable. Heavy rainfalls and floods affected the crop in Bihar and Orissa and in parts of the United Provinces. In Sind, the crop suffered from low intundation in the beginning of the season.

\section{GYPSUM DEPOSIT IN A BOILER}

With regard to the discussion on the setting of plaster and the importance of the hydrates of $\mathrm{CaSO}_{4}$ in this problem, it may be of interest to mention a recent case of deposit of practically pure gypsum, i.e., $\mathrm{CaSO}_{4} .2 \mathrm{H}_{2} \mathrm{O}$, in a boiler. The case is reported by Professor Goldberg in the Chemiker Zeitung. The boiler water had been run off and a little water had been left and had been concentrated to a mud and crystalline deposit in the course of half a year during which the boiler was not used. Over this crystalline deposit were found close, well-defined crystals of gypsum, colorless or slightly yellow and containing only 0.06 per cent of iron oxide and alumina. The crystalline deposit underneath also consisted largely of calcium sulfate but together with magnesia, oxide of iron, and silica. The occurrence of the hemi-hydrate $2 \mathrm{CaSO}_{4} \cdot \mathrm{H}_{2} \mathrm{O}$ in a boiler instead of the usually observed anhydrous salt was reported as long ago as 1838 . In boilers at pressures of several atmospheres, the $\mathrm{CaSO}_{4}$ is deposited as anhydrous salt; the gypsum crystals seem only to be formed at ordinary temperatures.

\section{REACTIONS OF ACETYLENE}

In a paper on "Some Reactions of Acetylene" read before the Society of Chemical Industry, London, Prof. W. R. Hodgkinson described the effect particularly on iron, cobalt, and nickel of passing acetylene and acetylene mixed with ammonia over the metal. With so-called pure gas the iron was not much affected but there was a great physical effect on nickel and cobalt. They became brittle and showed decided corrosion and pitting. With iron there was more or less deep carburization, this effect being slight in the case of the other two metals. The carbon from the acetylene was found to have actually entered the ferro-metals. The carburization was peculiar, the carbon showing distinct diffusion into the metal. When the acetylene was diluted with ammonia, an almost smokeless flame was produced and iron, nickel, and cobalt were more rapidly carburized than with acetylene alone. Cnfortunately, on subsequent heating, the metals remained brittle.

\section{MAGNESITES}

In the course of a paper read by Mr. W. Donald at the meeting of the Ceranic Society held at Stoke-on-Trent, England, the author stated that Greek magnesite has usually more silica and lime but much less ferric oxide than Australian magnesite. In the finely crystalline Greek magnesite, the mineral impurities -more especially oxide of iron and alumina-are distributed very irregularly. This increases the difficulty of satisfactorily calcining throughout in single firing. Canadian magnesites are even more irregular. In the author's opinion by the careful selection of material, Greek magnesite could be made to compare more favorably with Australian magnesite as regards lime and silica content.

\title{
WATER LUBRICATION OF GAS EXHAUSTERS
}

Mr. Guillet, in an article in Journal des Usines à Gaz, recommends, from lis own experience, the use of water in place of oil for the lubrication of exhausters. A steam-driven Beale exhauster put into use new in October 19 Io has been lubricated in this manner and, without having once been out of service, manifests no appreciable wear after having passed over rooo million cu. $\mathrm{ft}$. of gas. The lubrication has been effected by siphons delivering town water of great purity, but in general practice, according to Mr. Guillet, it is better to use ammoniacal liquor, since a hard water under the influence of ammonia and carbonic acid gas forms a deposit in the circular passages, causing a block and allowing for dismantling and scraping. With ammoniacal liquor the nuisance does not occur. Exhausters lubricated in this way have kept in excellent condition, the interior surface taking a high polish.

\section{UTILIZATION OF WASTE SULFITE LYE}

The disposal of the waste sulfite liquor in the manufacture of wood pulp or cellulose has long been a perplexing problem. Recent experiments, says the Pulp and Paper Magazine, have demonstrated that this waste sulfite liquor can be evaporated to dryness and the solid substance thereby obtained may be subjected to calcining and burning. The gases coming off may be trapped and the ashes treated for the recovery of the sulfur as well as the basic substances present in the original bisulfite liquor. Incidentally, and of great economic importance, it may be mentioned that the dry residue produces a fuel containing approximately 6000 B. t. u. per lb. A mill with a capacity of 50 tons of pulp per day will discharge 500 tons of waste sulfite liquor daily containing Io per cent of organic matter which may be thus reclaimed. The fuel available would have a heat value equivalent to that of 25 tons of high-grade $(24,000$ B. t. u.) coal. With a view to eliminating entirely the disadvantages of burning over grates, tests have recently been made of burning the material in suspension.

\section{COAL SAVING}

The February number of the monthly publication of the British Commercial Gas Association deals with the use of gas coke for steam raising. It contains an article giving a large number of particulars which go to prove the economy alike from an individual and a national point of view, effected by the use of coke instead of crude coal in steam-raising plants. Illustrations are given which show the number, variety, and importance of commercial and other undertakings which have already made the change to great advantage. An interesting section of the article deals with the use of coke as a fuel for road transport in which capacity it is being largely employed to-day.

\section{BRITISH BOARD OF TRADE}

During the month of March, the British Board of Trade have received inquiries regarding sources of supply for the following articles. Firms able to give information about these things are requested to communicate with the Board of Trade, 73 Basinghall St., London, E. C.

Bead necklaces, ladies Celluloid, clear, transparent (sheet form)

Cigarette holders (tortoise shell)

Copper asbestos washers Combined pens and pencil Flat pencils with sheath Ink-pots with soluble safety lids Ink-pots with soluble safe
Map-cases (for officers) Map-cases (for officers) Petrol and tinder lighters Spangles for dress decoration Sprinklers for perfume bottles
Steel strip $(3 / 8$ in. to $1 / 2$ in. wide $\times 20$ to $28 \mathrm{~B}$. W. G. put up on reels) Sulfite pitch

Thermostats, automatic for electric incubators

Wholsterer's springs and petrol Wheels for

MAchineRy AND PLANT For MAKING: Screw parts of cork-screws Snuff Shellac and sticklime Starch 